\title{
Presencia, distribución y ataques de los ofidios venenosos del Chocó Biogeográfico: Una ventana a la bioprospección de los recursos genéticos de la región
}

\section{Presence, distribution and attacks of the poisonous ofidio of it Chocó Biogeographic: A window to the bioprospección of the genetic resources of the region}

\author{
Rosemary Martínez ${ }^{1}$, Karina Machado 2

\section{RESUMEN}

El envenenamiento ofídico se relaciona con actividades de campo como agricultura o minería, de ahí que en la actualidad aún se presenten accidentes ofídicos en las comunidades negras e indígenas asentadas en todo el Chocó Biogeográfico. Buscando levantar y sistematizar información científica sobre presencia, distribución y ataques de ofidios venenosos en esta región, se realizó un estudio de las principales especies, mediante una revisión detallada de las bases de datos de fauna de diferentes universidades y bases de datos del Sistema Vigilancia Epidemiológica (SIVIGILA) del Ministerio de la Protección Social así como las secretarías de salud departamentales donde se revisaron cada uno de los ejemplares de ofidios colectados que reposan en los laboratorios de zoología de las mismas, y artículos científicos, tesis de grados, y revistas institucionales. Se diseñó una base de datos en Excel-2007 teniendo en cuenta la ecología, características, morfología, distribución y densidad poblacional de ofidios venenosos por especie; se aplicaron encuestas con la participación de los concejos comunitarios del sur, norte y centro del Chocó Biogeográfico. Todo esto permitió obtener una caracterización de las especies presentes en la región y una base de datos que incluye su distribución, frecuencia de ataque, mortalidad y disponibilidad del suero.

Palabras clave: Ofidios; Suero; Antiofídico; Distribución; Ataque.
1. Bióloga, Profesional responsable, Universidad Tecnológica del Chocó, Colombia. e-mail: rosemaryuib@hotmail.com

2. Bióloga, Profesional responsable, SENA Regional Chocó, Colombia. e-mail: monares1980@ hotmail.com Recibido: febrero 26, 2009 Aceptado: marzo 12, 2009

\begin{abstract}
The ofidico envenenamiento is related to activities of field like agriculture or mining, for that reason at present ofidicos accidents in seated the black and indigenous communities in all the Biogeographic Chocó even appear. Looking for to raise and to systematize scientific information on presence, distribution and attacks of poisonous ofidios in this region a study of the main species of the region was realised, by means of a detailed revision of the data bases offauna of different universities and data bases from the System Monitoring Epidemiologist (SIVIGILA) of the Ministry of the Social Protection as well as the departmental secretaries of health, reviewed each one of the unit of collected ofidios that rest in the laboratories of zoology of the same; in addition, scientific articles, institutional theses of degrees, and magazines. A data base in Excel-2007 was designed considering ecology, characteristics, morphology, distribution and population densidad of poisonous ofidios by species, were applied surveys with the participation of the communitarian councils of the south, north and center of Biogeographic Chocó. All this allowed obtaining
\end{abstract}




\section{Ataques de ofidios venenosos. R. Martínez, K. Machado}

a characterization of the present species in the region and a data base that includes their distribution, frequency of attack, mortality and availability of the serum.

Keysword: Ofidios; Serum; Antiofidico; Distribution; Attack.

\section{INTRODUCCIÓN}

Las serpientes venenosas y sus presas han coexistido durante aproximadamente 200 millones de años y a pesar de que el ser humano no hace parte de su cadena alimenticia, el contacto del hombre con éstas hace que el envenenamiento ofídico todavía sea una causa importante de morbilidad y mortalidad en el país. El envenenamiento ofídico es una condición prevalente relacionada con actividades de campo (agricultura, ganadería, minería) en regiones tropicales como Valle del Cauca, Cauca, Nariño y Chocó (Castrillonet al.2007).

En la actualidad existen en Colombia 238 especies de serpientes de las cuales 40 son venenosas, las más comunes son las cuatronarices, también llamadas mapanaes, equis o boquidorás, cascabeles, las pudridoras o verrugosos y corales. Además se encuentra la serpiente marina del Pacífico (Pelamis platurus) ( Otero et al. 1992). Los accidentes ofídicos ocurren sobre todo en zonas de clima cálido donde se ubican los ecosistemas en que es más probable encontrar serpientes, aumentándose el riesgo por deforestación, colonización, almacenamiento de cosechas y víveres e incorrecta disposición de basuras que atraen a roedores y con ellos a las serpientes. Estas con más frecuencia en las temporadas de lluvias, porque se ven obligadas a abandonar sus refugios, desplazándose a sitios secos, entre los que pueden estar las habitaciones humanas y sitios aledaños (Otero et al. 1992).

En la actualidad se siguen presentando muchos accidentes ofídicos en especial en las comunidades negras e indígenas asentadas en todo el Chocó Biogeográfico las cuales utilizan su saber ancestral mágico-religioso para contrarrestar el letal veneno de los ofidios, porque en muchas comunidades no existe un centro de salud y en las pocas que hay, no se cuenta con suero antiofídico (Oteroet al. 2000). Desde octubre de 2004, el Ministerio de Protección Social de Colombia lo declaró evento de notificación obligatoria, la cual se realiza porel Sistema de Vigilancia Epidemiológica (SIVIGILA) (Anexo 1), (Instituto Nacional de Salud 2007). Informes recientes facilitan comprender el mecanismo de acción de los diferentes venenos, describiendo la toxicidad local, hemorrágica, nefrotóxica e hipotensora del veneno bothrópico, neurotoxicidad vagal del veneno lachésico, mionecrolítica y neurotóxica del veneno crotálico y capacidad paralizante del elapídico, siendo estos los géneros responsables de1 99\% de los envenenamientos en Colombia, destacándose el bothrópico, con 90-95\% de los casos (Otero et al. 2002).
En la actualidad en Colombia el suero antiofídico puede ser: - Monovalente: Usados exclusivamente para la mordedura de un solo tipo de serpientes y pueden ser:

- Antibotrhopico: Contra la mordedura de mapaná, taya x, cuatro narices.

- Anticrotalico: Contra mordedura de cascabel.

- Antilachesico: Contra mordeduras de verrugosa, surucucú.

- Anticoral: Contra mordedura de corales.

- Polivalente: Se utiliza para tratamiento provocado por accidentes Bothrópico (mapaná), Crotálico (cascabel) y en algunos sueros por reacción cruzada el Lachésico (verrugosa).

\section{AREA DE ESTUDIO}

Con este nombre los ambientalistas, geógrafos y biólogos ante todo, denominan a un territorio comprendido desde el sur de Honduras, hasta el norte del Perú. Se trata de una de las tierras bajas (West 1954) caracterizada por su altísima pluviosidad, hasta $12000 \mathrm{~mm}$ anuales en el departamento del Chocó, Colombia, y una exuberante diversidad biológica considerada la más alta del planeta.

La porción perteneciente a Colombia, ubicada en la frontera panameña, al noroeste, hasta los límites con la República del Ecuador, al sur. Al oeste la falda occidental de la cordillera del mismo nombre y al noreste con los confines de la serranía de Abibe en su agonía en el mar de Caribe. Este territorio es producto del choque de las placas tectónicas de los Andes occidentales, la del Pacífico y la del Caribe, lo cual dio por resultado la emersión de los suelos ya mencionados, trayendo por consecuencia la desaparición del antiguo canal natural que comunicaba al Pacífico y el Atlántico a la altura del departamento del Chocó; al sur de éste apareció la llanura del Pacífico. Esta estrecha región involucra áreas de los departamentos de Córdoba, todo el Urabá o Darién oriental, todo el departamento del Chocó, la costa vallecaucana, la misma del Cauca y Nariño y el municipio de Pueblo Rico en Risaralda, (Perea 2002).

La espesura del bosque y la lluvia constantes conforman la vertiente del Pacifico colombiano, una intrincada red de ríos que desembocan en el océano, uno de ellos es el río San Juan que corre hacia el sur atravesando las selvas más húmedas del planeta para desembocar en el Océano Pacífico, el segundo, uno de los río más importantes de Colombia, es el Río Atrato «con sus $4.900 \mathrm{~m}^{3} / \mathrm{segundo}$ corre hacia el norte por entre planicies que forman ciénagas y pantanos estacionales que le dan nombre al llamado Tapón del Darién en la frontera con Panamá». En el Chocó Biogeográfico habitan negritudes y grupos de indígenas como los Cuna, Embera, Waunama, Kwaiker quienes viven en medio de la riqueza biótica y abiótica del corredor (Amatea 2004). 


\section{Bioetnia Volumen 6 № 1 (enero-junio), 2009}

\section{MÉTODOS}

Para el levantamiento de la información científica sobre presencia y distribución se hizo una revisión detallada de las bases de datos de fauna de la Universidad Tecnológica del Chocó, del Instituto de Ciencias Naturales, Universidad del Valle y Universidad del Pacífico; se revisaron cada uno de los ejemplares de ofidios colectados que reposan en los laboratorios de zoología de las misma; además, artículos científicos, tesis de grados, y revistas institucionales.

Para la compilación de la información de ofidios venenoso reportados en el Chocó Biogeográfico se tomo como base la información generada en la actividad anterior se depuro la información, se hizo un análisis de sinonimias y se descarto la duplicidad de información, luego se procedió a listar las especies de ofidios venenosos por departamentos, con su respectiva localidad de colección y una descripción ecológica de cada especie.

Para el diseño de la base de datos se utilizó el programa Exel-2007 teniendo en cuenta ecología, características, morfología, distribución y densidad poblacional de ofidios venenosos por especie. Para complementar la información secundaria se diseño un formato de encuesta con la participación de los concejos comunitarios del sur del Chocó Biogeográfico (Guapi y Timbiquí) y otra con los consejos comunitarios del norte y centro (COCOMACIA, ASOCASAN, RISCALES y DELFINES).La recolección, revisión de registros de ataques de ofidios y la cobertura del uso del suero antiofídicos en la zona de estudio, se obtuvo mediante la revisión detallada de la base de datos de Sistema de Vigilancia Epidemiológica (SIVIGILA) del Ministerio de la protección social y la información suministrada por el Instituto Departamental de Salud de Nariño, Departamento Administrativo de Salud de Chocó, Secretaría de Salud de Risaralda, Secretaría de Salud del Cauca, Secretaría de Salud de Antioquia y Secretaria de Salud del Valle del Cauca.

La definición de puntos críticos con mayor frecuencia de ataques ofídicos en la zona de estudio se realizó teniendo en cuenta la información científica sobre presencia y distribución de las especies de ofidios venenosos. Finalmente se creó una base de datos en Exel-2007 a partir de la distribución de especies, número de ataques, frecuencia de ataque, mortalidad y disponibilidad del suero.

\section{RESULTADOS Y DISCUSIÓN}

Composición, distribución y presencia de ofidios venenosos. Se encontró que la totalidad de las serpientes venenosas que se informan para el Chocó Biogeográfico colombiano se encuentran distribuidas en 18 especies, ocho géneros y tres familias, Viperidae, Hydropiidae y Elapidae, siendo esta última la de mayor presencia en la zona de estudio, lo cual se demuestra por su amplia distribución geográfica (departamentos del Chocó, Valle del Cauca, Antioquia, Risaralda, Cauca y Nariño) (Tabla 1), esto puede ser explicado por la variedad de ambientes en el que ocurren estas, apreciación que ratifica las observaciones de Rentería (2006), quien relaciona la diversidad de la familia con la utilización de diversos tipos de hábitats y microhábitats. Las especies que hacen presencia en el Chocó Biogeográfico colombiano son: Micrurus ancoralis, Micrurus clarki, M. dissoleucus, $M$. dumerilii, M. mipartitus, M. multifasciatus, M. multiscutatus, M. nigrocinctus, M. spurrelli, Pelamis platurus, Bothriechis schlegelii, Bothriopsis punctata, Bothrocophias myersii, Bothrops asper, B. punctatus, Lachesis muta, P. lansbergii, Porthidium nasutum (Anexo 1).

Ataques de ofidios registrados por comunidades rurales del Chocó Biogeográfico. En elChocó Biogeográfico colombiano existe un vacío de información sobre ataques de ofidios, porque sólo a partir del año 2004 el Ministerio de la Protección Social lo hizo a través del evento de notificación obligatoria en SIVIGILA. Se encontró que en el año 2004, se notificaron 5 casos de accidentes ofídicos confirmados clínicamente, los cuales se distribuyeron por departamentos de la siguiente manera (SIVIGILA-ISN): Nariño 3 casos, Cauca y Chocó 1 caso respectivamente, resaltando que en ninguno de ellos se presentó mortalidad. Este reporte tan escaso se debe a que sólo en este año se presentó el evento de notificación obligatoria y no se había instalado el software del SIVIGILA en las secretarias de salud departamentales, porque de acuerdo con la literatura, el Chocó Biogeográfico presenta una mayor incidencia de accidentes ofídicos.

En el año 2005 se notificaron 227 casos de accidentes ofídicos confirmados clínicamente, los cuales se distribuyeron por departamentos de la siguiente manera (SIVIGILAISN): Cauca 92 (40\%) casos, Valle del Cauca 68(30\%), Nariño $36(16 \%)$ y Chocó 31 (14\%) casos. Este informe fue significativo en comparación con el año anterior y el departamento del Cauca presentó el mayor número de accidentes ofídicos con 92 casos. Se presentaron dos casos de mortalidad, uno en el departamento del Chocó en el municipio de Riosucio y el otro en el Valle del Cauca en el municipio de Ulloa.

Para el año 2006 se notificaron 235 casos de accidentes ofídicos confirmados clínicamente, distribuidos según el SIVIGILA-ISN en $95(41 \%)$ casos en el departamento de Cauca, 71 (30\%) en Nariño, 45 (19\%) en el Valle del Cauca y $24(10 \%)$ casos en el departamento del Chocó. Esto muestra que el departamento del Cauca presenta en dos años consecutivos el mayor número de reportes de accidentes ofídicos, lo cual puede estar relacionado con la vocación agraria y ganadera significativa de este departamento. Sólo se presentó un evento mortal localizado en el departamento del Chocó en el municipio de Unguía.

En el año 2007 se notificaron 191 casos de accidentes 
Tabla 1

Especies y distribución de ofidios venenosos en el Chocó Biogeográfico colombiano

\begin{tabular}{|c|c|c|c|c|c|c|}
\hline Especies & Chocó & Valle del Cauca & Antioquia & Risaralda & Cauca & Nariño \\
\hline Micrurus ancoralis & $x$ & $x$ & & & $x$ & $x$ \\
\hline Micrurus clarki & $x$ & & & & $x$ & $x$ \\
\hline Micrurus dissoleucus & $x$ & & & & & \\
\hline Micrurus dumerilii & $x$ & $x$ & $\mathrm{x}$ & $x$ & $x$ & \\
\hline Micrurus mipartitus & $x$ & $x$ & $x$ & $x$ & $x$ & \\
\hline Micrurus multifasciatus & & $x$ & & & & \\
\hline Micrurus multiscutatus & $x$ & $x$ & & & $x$ & \\
\hline Micrurus nigrocinctus & & & $\mathrm{x}$ & & & \\
\hline Micrurus spurrelli & $x$ & & & & & \\
\hline Pelamis platurus & $x$ & $\mathrm{X}$ & & & $\mathrm{X}$ & \\
\hline Bothriechis schlegelii & $x$ & $x$ & & & $x$ & $\mathrm{x}$ \\
\hline Bothriopsis punctata & $\mathrm{x}$ & $x$ & $\mathrm{x}$ & & $\mathrm{x}$ & $x$ \\
\hline Bothrocophias myersii & & $x$ & & & $x$ & \\
\hline Bothrops asper & $\mathrm{X}$ & $x$ & & $x$ & $x$ & \\
\hline Bothrops punctatus & $x$ & & & & & \\
\hline Lachesis muta & $\mathrm{X}$ & $x$ & & $X$ & $\mathrm{X}$ & $x$ \\
\hline Porthidium lansbergii & $x$ & & $x$ & & & \\
\hline Porthidium nasutum & $\mathrm{x}$ & $x$ & $\mathrm{X}$ & & & $\mathrm{x}$ \\
\hline
\end{tabular}

ofídicos confirmados clínicamente, de los cuales 86 (44\%) casos se presentaron en Nariño, 63 (33\%) en Valle del Cauca, 21 (11\%) en el Chocó, 20 (10\%) en el Cauca y 3 (2\%) casos en Antioquia (SIVIGILA-ISN). Para este período el departamento de Nariño presenta el mayor número de accidentes ofídicos con 86 casos.

Se presentaron 4 casos de mortalidad, uno el departamento del Chocó en el municipio de Quibdó y 3 en el departamento de Antioquia distribuidos en los municipios de Mutatá, Vigía del Fuerte y Chigorodó (Figura 1).

Se encontró que la especie agresora con mayor reporte clínico de accidente ofídico en el Chocó Biogeográfico es Botrhops asper, que se encuentra en 99\% de los casos, seguida de la Pelamis platurus con 1\% de los casos. Esta información coincide con lo citado en el SIVIGILA-ISN y se debe a diversas razones, entre las que se puede mencionar que en las áreas con mayor frecuencia de accidente, al momento de presentarse no se observa la especie agresora y no se captura la misma, falta de información de la especie y al llenar el formato no se hacen todas las preguntas de rigor, el personal médico da por supuesto que todos los accidentes son ocasionados por Botrops asper debido a que es la especie que más predomina en la zona o la gran mayoría de los pacientes mencionan a equis o mapaná como las especies que

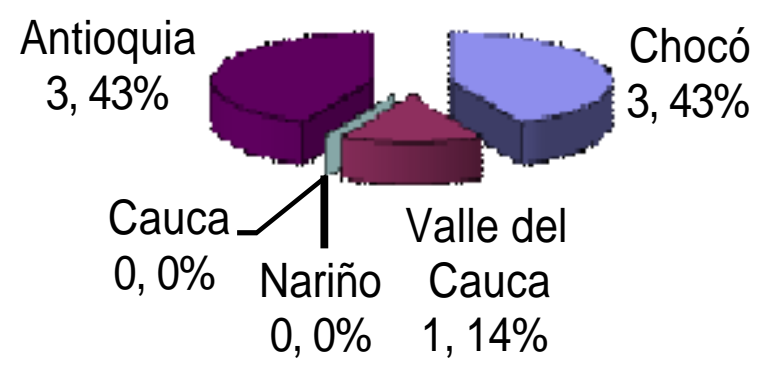
Figura 1. Muertes por accidentes ofídicos reportadas en el Chocó Biogeográfico. 2004 a 2007

los atacan con más frecuencia.Se reportó mortalidad en tres departamentos, Antioquia y Chocó con 3 casos respectivamente y sólo uno en el Valle del Cauca, lo que significa que aunque el departamento del Chocó y Antioquia tienen el menor número de registro de accidentes ofídicos, presentan el mayor número de mortalidad confirmando lo reportado en la literatura (SIVIGILA-ISN). Se observa que el reporte de accidentes ofídicos del año 2004 no fue significativo porque durante ese período las secretarías de salud departamentales no reportaron la información total correspondiente (SIVIGILA-ISN); sólo para este año se declaró el accidente ofídico un evento de notificación obligatoria, el cual se realiza 


\section{Bioetnia Volumen 6 № 1 (enero-junio), 2009}

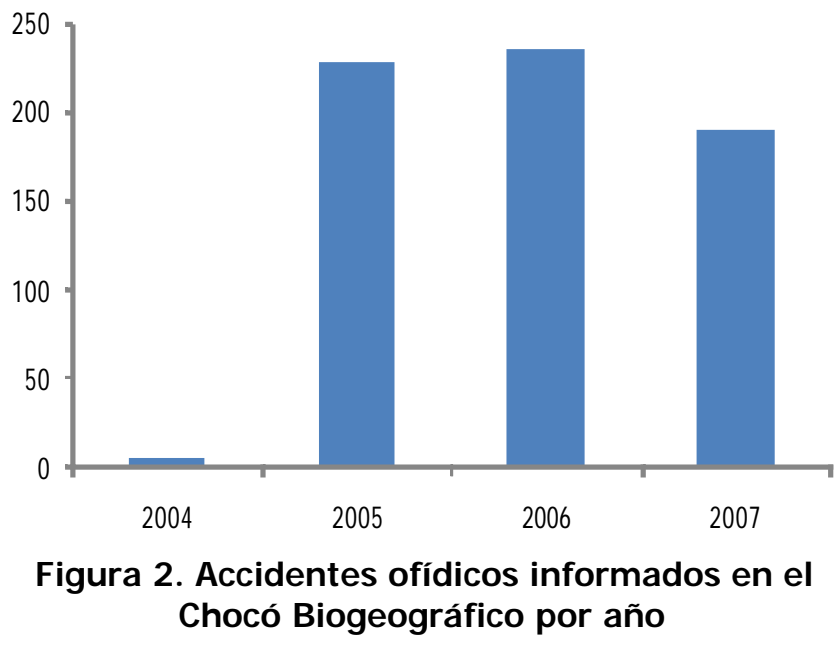

por el SIVIGILA que funciona por semanas epidemiológicas y la información se informa anualmente de la primera semana de enero a la última de diciembre, de allí se explica el pobre registro del año 2004 y el aumento gradual de información porque sólo hasta 2006 se realizó la socialización en todo el país (Figura 2).

Teniendo en cuenta la información recolectada, el departamento con mayor frecuencia de ataque de ofidios venenosos es el departamento del Cauca con 208 casos seguido de Nariño con 196, Valle del Cauca con 176, Chocó con 77 y Antioquia con 3 casos (Tabla 2). Esto se debe a la gran vocación agrícola del Cauca porque la gran mayoría de los accidentes se presentan realizando estas actividades (Castrillon et al. 2007).

Según lo reportado por las secretarias de salud departamentales la disponibilidad de suero antiofídico en el Chocó Biogeográfico es deficiente porque el Ministerio de la Protección Social para suministrarlo se basa en los reportes de accidentes presentado por las mismas, sumado a que el suero polivalente que se produce en el país es líquido, lo que exige que se mantenga en unas condiciones de cadena de frío que no se cumplen en zonas con problemas de prestación de servicio de energía eléctrica como en muchas localizadas en el Chocó Biogeográfico, lo que evita que se tengan una reserva de los sueros y se incrementen las tasas de mortalidad por este tipo de accidentes. De allí que se encontró que $60 \%$ de las víctimas de mordeduras de serpientes son inicialmente tratados por medicina tradicional (curanderos o chamanes), usando plantas medicinales de diferentes formas de acuerdo con el estado clínico del paciente (conversación personal 2008).

Los estudios más recientes y rigurosos, así como la experiencia médica, han demostrado que la mayoría de las recomendaciones para atender casos de envenenamiento ofídico nos son aplicadas correctamente, lo que incrementa el número de muertes. Dentro de las recomendaciones para los primeros auxilios están: no efectuar ningún tipo de incisión pues aumenta riesgo de infección y sangrado, no realizar succión, ya que favorece infección y no se remueve gran cantidad de veneno, evitar la utilización de torniquetes pues complica más la irrigación a zonas distales e incrementando la isquemia. Tampoco administrar compresas de hielo ni descargas eléctricas de ningún tipo y evitar la administración de sustancias químicas o extractos de plantas por ninguna vía al paciente mordido, como se realiza en muchas comunidades de la región. Los primeros auxilios se deben reducir a inmovilizar lo más posible la extremidad afectada y a trasladar al paciente al hospital o centro médico más cercano para que se le aplique el suero antiofídico (conversaciónpersonal-2008).

Se encontraron notables falencias en los reportes de accidentes ofídicos por el mal manejo que se la ha dado a la ficha de notificación de los mismos, esto se debe a la falta de inducciones a los médicos y todas las personas que conforman la red hospitalaria. A lo anterior se agrega que la mayoría de los pacientes son atendidos por médicos recién egresados que desconocen el tema, el panorama se vuelve más crítico.

\section{CONCLUSIONES}

En elChocó Biogeográfico colombiano se encontraron 18 especies venenosas representadas en tres familias de serpientes, Elapidae, Viperidae y Hydropiidae siendo la familia Elapidae la de mayor presencia en la zona de estudio demostrando que por su ubicación geográfica estas especies hacen más presencia en Chocó, Valle del Cauca y Cauca. Las especies que hacen presencia en el Chocó Biogeográfico colombiano son: Micrurus ancoralis, Micrurus clarki, Micrurus dissoleucus,Micrurus dumerilii, Micrurus mipartitus, Micrurus multifasciatus, Micrurus multiscutatus, Micrurus nigrocinctus, Micrurus spurrelli, Pelamis platurus, Bothriechis schlegelii, Bothriopsis punctata, Bothrocophias myersii, Bothrops asper, Bothrops punctatus, Lachesis muta, Porthidium lansbergii, Porthidium nasutum.

La declaración de los accidentes ofídicos como eventos de notificación obligatoria a través del SIVIGILA, que funciona por semanas epidemiológicas y reporta anualmente los casos, explica el pobre registro de 2004 y el aumento gradual de información porque sólo hasta 2006 se realizó la socialización en todo el país.

La especie agresora con mayor reporte clínico de accidente ofídico en el Chocó Biogeográfico es Botrhops asper con un $99 \%$ de los casos, seguida de la Pelamis platurus con $1 \%$ de los casos, debido a la falta de identificación de las especies en el momento del ataque, errores en el diligenciamiento de formatos y reportes errados por parte de la comunidad.

Los reportes de accidentes ofídicos encontrados en el SIVIGILA de 2004 a 2007 de muestran que el departamento con mayor novedad es Cauca con 208 casos, seguido de Nariño 
Tabla 2

Número de casos de accidentes ofídicos reportados en el Chocó Biogeográfico con frecuencia de ataque alta y disponibilidad del suero

\begin{tabular}{|c|c|c|c|c|c|c|c|}
\hline \multirow[t]{2}{*}{ Departamento } & \multirow[t]{2}{*}{ Municipio } & \multicolumn{4}{|c|}{ Número de casos reportados por años } & \multirow[t]{2}{*}{ Mortalidad } & \multirow[t]{2}{*}{ Especie } \\
\hline & & 2004 & 2005 & 2006 & 2007 & & \\
\hline \multirow{7}{*}{ Chocó } & Carmen de Atrato & 1 & - & - & - & No & Botrhops asper \\
\hline & Desconocido & - & 30 & - & - & No & Botrhops asper \\
\hline & Riosucio & - & 1 & - & - & 1 & Botrhops asper \\
\hline & Desconocido & - & - & 23 & - & No & Botrhops asper \\
\hline & Unguía & - & - & 1 & - & 1 & Pelamis platurus* \\
\hline & Desconocido & - & - & - & 20 & No & Botrhops asper \\
\hline & Quibdó & - & - & - & 1 & 1 & Botrhops asper \\
\hline \multirow{4}{*}{ Valle del Cauca } & Desconocido & - & 67 & - & - & No & Botrhops asper \\
\hline & Ulloa & - & 1 & - & - & 1 & Botrhops asper \\
\hline & Desconocido & - & - & 45 & - & No & Botrhops asper \\
\hline & Desconocido & - & - & - & 63 & No & Botrhops asper \\
\hline \multirow{6}{*}{ Nariño } & Aldana & 1 & - & - & - & No & Botrhops asper \\
\hline & Los andes & 1 & - & - & - & No & Botrhops asper \\
\hline & Tumaco & 1 & - & - & - & No & Botrhops asper \\
\hline & Desconocido & - & 36 & - & - & No & Botrhops asper \\
\hline & Samaniego & - & - & 71 & - & No & Botrhops asper \\
\hline & Desconocido & - & - & - & 86 & No & Botrhops asper \\
\hline \multirow{4}{*}{ Cauca } & Balboa & 1 & - & - & - & No & Botrhops asper \\
\hline & Desconocido & - & 92 & - & - & No & Botrhops asper \\
\hline & Desconocido & - & - & 95 & - & No & Botrhops asper \\
\hline & Desconocido & - & - & - & 20 & No & Botrhops asper \\
\hline \multirow{4}{*}{ Antioquia } & Vigía del & & & & & & \\
\hline & Fuerte & - & - & - & 1 & 1 & Botrhops asper \\
\hline & Chigorodo & - & - & - & 1 & 1 & Botrhops asper \\
\hline & Mutata & - & - & - & 1 & 1 & Botrhops asper \\
\hline Total & & 5 & 227 & 235 & 191 & 5 & \\
\hline
\end{tabular}

${ }^{*}$ Frecuencia de ataque baja

con 196, Valle del Cauca 176, Chocó con 77 y Antioquia con 3 casos. Se informó mortalidad en tres departamentos, Antioquia y Chocó con 3 casos cada uno y el Valle del Cauca con un caso. Lo que significa que aunque el departamento del Chocó y Antioquia tienen el menor número de registro de accidentes ofídicos presentan el mayor numero de mortalidad confirmando lo reportados en la literatura.

Las secretarias de salud departamentales reportan baja disponibilidad de suero antiofídico en el Chocó Biogeográfico, porque su suministro por parte del Ministerio de la protección Social, se basa en los informes de accidentes presentados por las mismas y a que en muchas zonas no se cuenta con las condiciones adecuadas para su almacenamiento. De allí que $60 \%$ de los de las victimas de mordeduras de serpientes sean inicialmente tratados con medicina tradicional.

\section{RECOMENDACIONES}

Es de vital importancia el levantamiento de mayor información con metodologías participativas, que permiten cono- cer a fondo la diversidad de especies de ofidios de la región del Chocó Biogeográfico para ampliar los resultados del presente estudio y corroborar las especies encontradas.

- Es importante que cada uno de los involucrados en la recopilación de la información se les capacite constantemente sobre la importancia de los accidentes ofídicos, no sólo como tratar los casos sino la recopilación de la información que es fundamental para determinar aspectos importantes como la especie, lugar, tiempo transcurrido, suero, actividad realizada al momento del accidente, síntomas, etc.

Esta información lleva a reorganizar el sistema de vigilancia de accidente ofídico desde su nivel más básico como es la recolección primaria de los datos hasta los niveles más complejos departamentales de almacenamiento, procesamiento y análisis de la información epidemiológica recolectada a través de la formulación de los lineamientos que cada departamento y municipio de acuerdo con sus competencias. 
Implementar programas de capacitación sobre el uso de la ficha de información de reporte ofídico de salud que sea extendido no sólo a los médicos sino también a la comunidad

\section{LITERATURA CITADA}

Perea, R. 2002. El Chocó Biogeográfico. Centro Afrocolombiano, Universidad Tecnológica del Chocó, Quibdó.

Fundación Amatea. 2004. El Chocó Biogeográfico. http://www.amatea.org/ choco

Castrillón, D., Acosta, J., Hernández, E., Palacio, L. 2007. Envenenamiento ofídico. Salud Uninorte. 23 (1): 96-111.
Otero, R., Tobón, GS., Gómez, L. F. 1992. Accidente ofídico en Antioquia y Chocó. Aspectos clínicos y epidemiológicos (marzo de 1989-febrero de 1990). Acta Med Colomb. 17: 229-49.

Otero, R., Núñez, V., Barona, J., Díaz, B., Saldarriaga, M. 2002. Características bioquímicas y capacidad neutralizante de cuatro antivenenos polivalentes frente a los efectos farmacológicos y enzimáticos del veneno de Botrops asper y Porthidium nasotum de Antioquia y Chocó.Iatreia. 15 (1):5-15.

Otero, R., Callejas, M.E., Gutiérrez, J., Villa, N.H. 2000. Necesidades reales de antivenenos en Colombia. Características de los productos y del mercado. Rev Epidemiol Antioquia. 26: 49-59.

Ministerio de Protección Social. 2004-2007. Sistema de Información para la Vigilancia en Salud Pública (SIVIGILA). http://www.minproteccionsocial. gov.co

Anexo 1

Descripción y ubicación de las especies que hacen presencia en el Chocó Biogeográfico colombiano

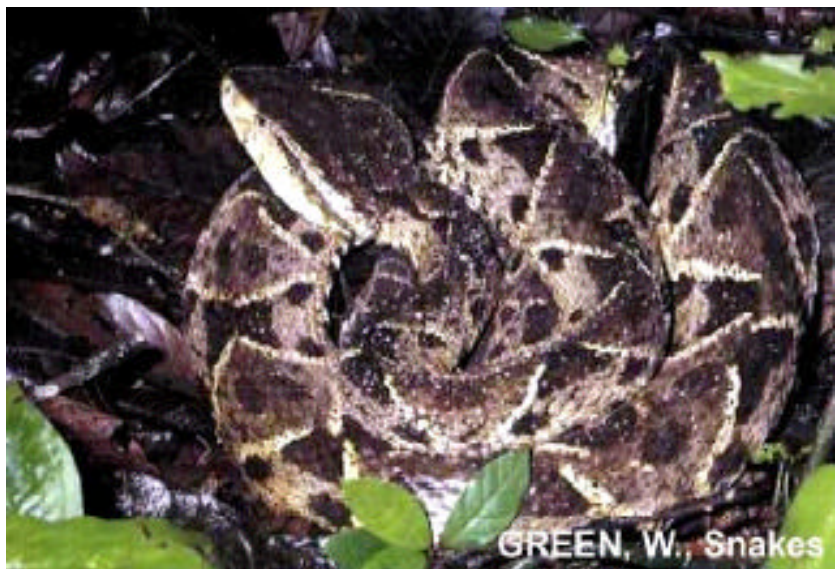

Bothrops asper

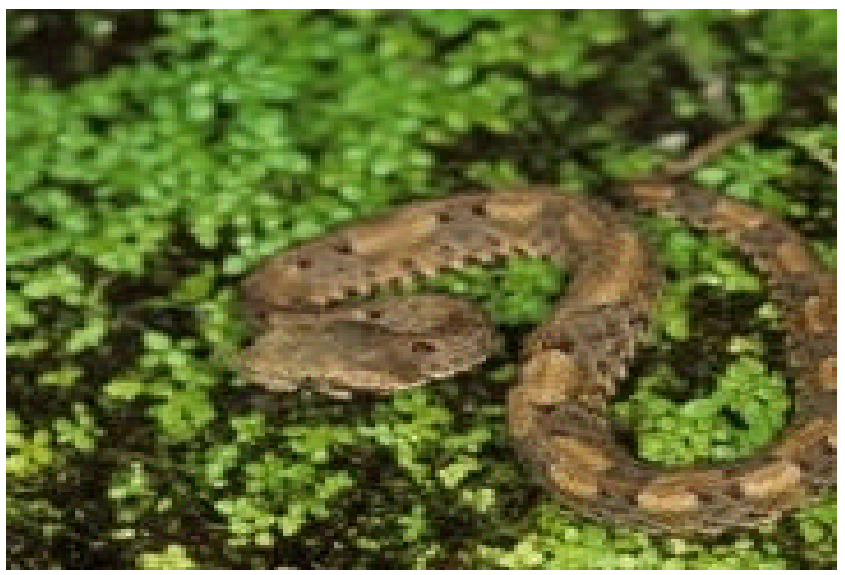

Bothriopsis punctata

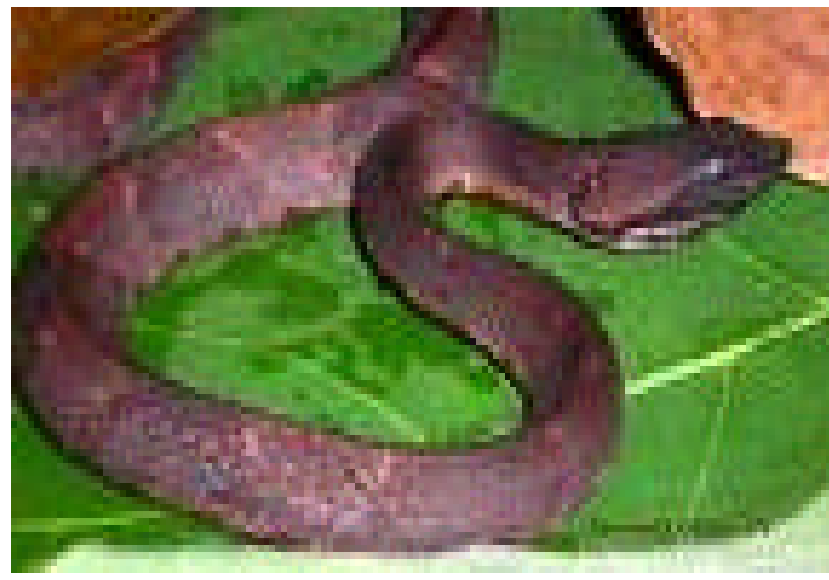

Bothrocophias myersii

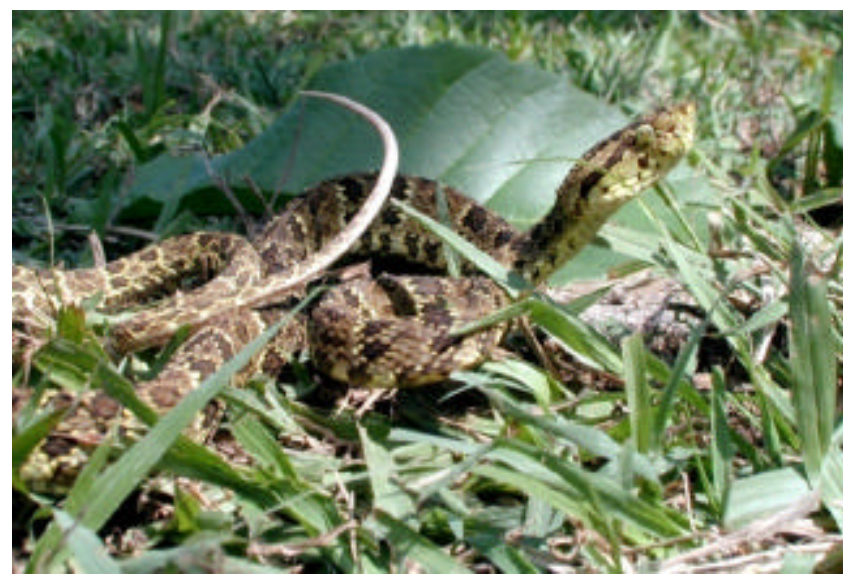

Bothrops punctatus 
Ataques de ofidios venenosos. R. Martínez, K. Machado
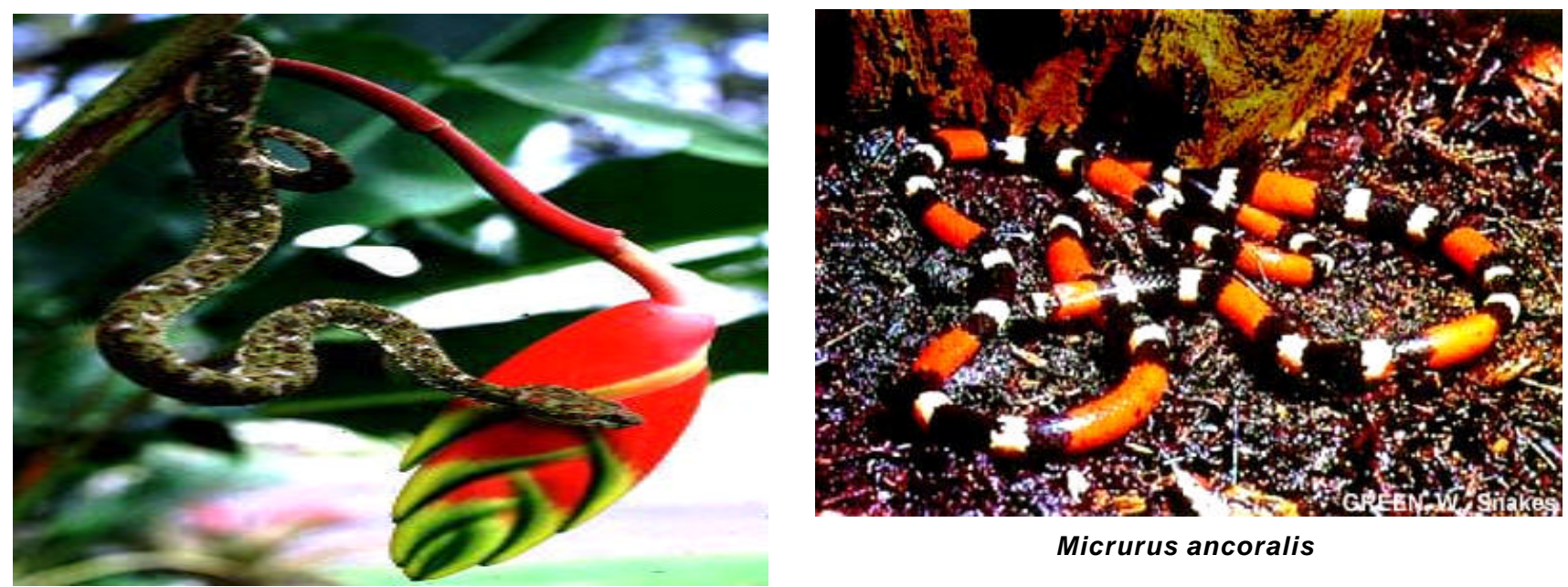

Bothriechis schlegelii

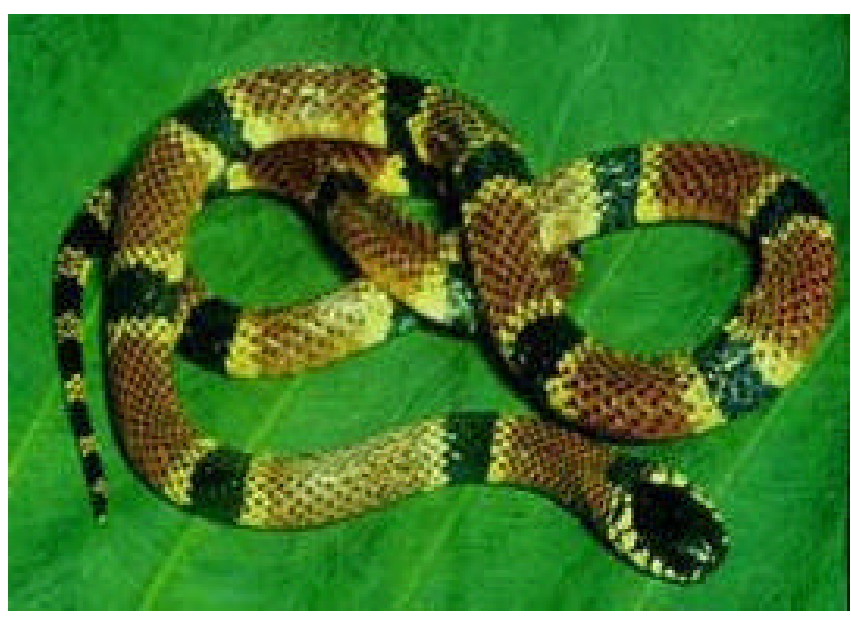

Micrurus clarki

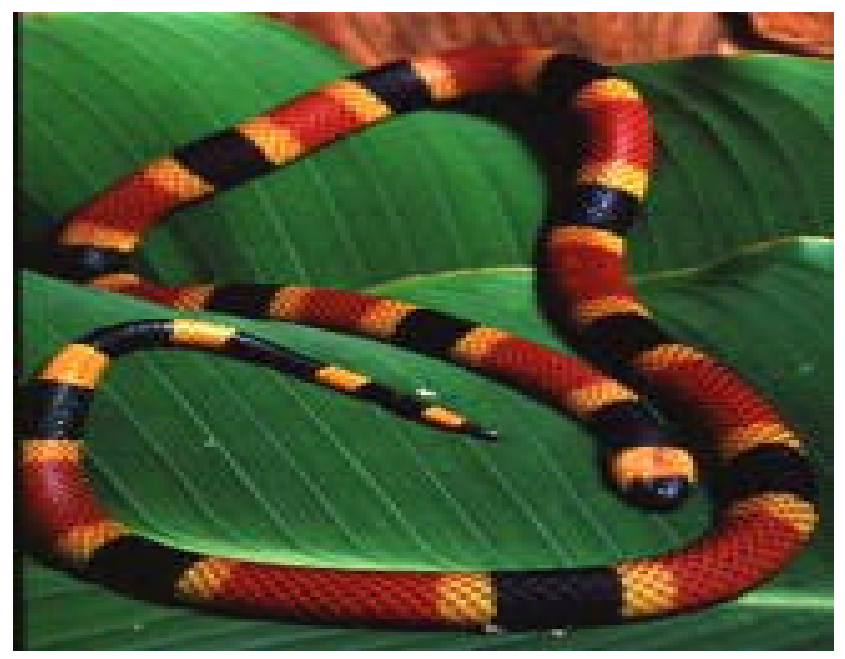

Micrurus dumerilii

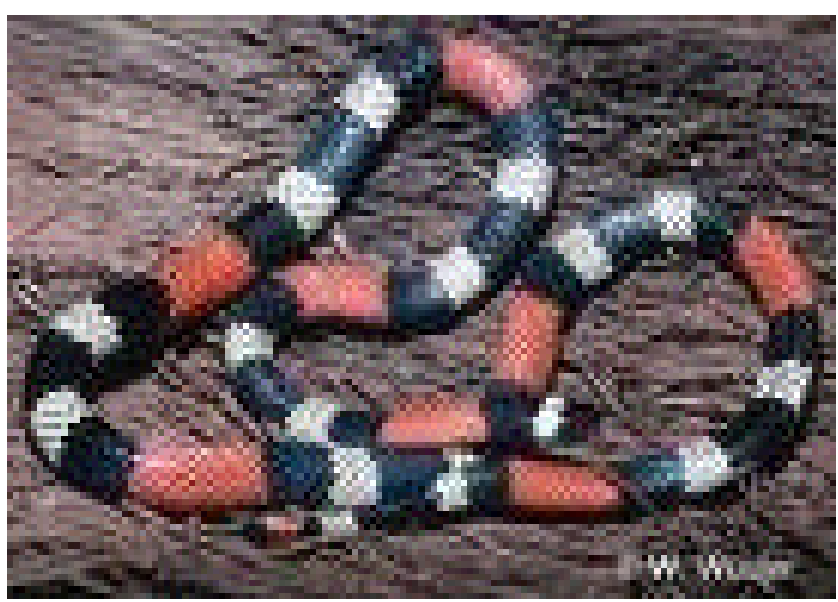

Micrurus dissoleucus

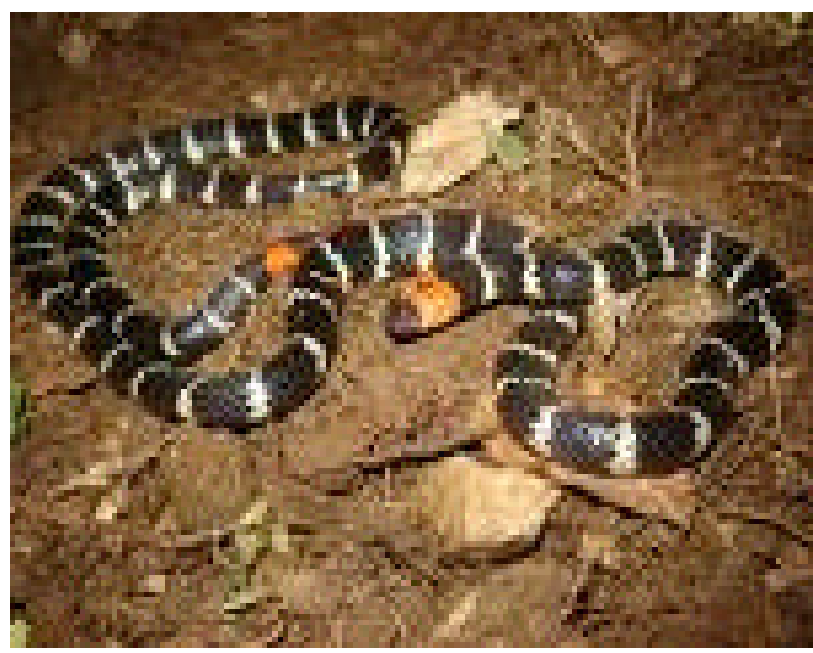

Micrurus mipartitus 
Bioetnia Volumen 6 № 1 (enero-junio), 2009

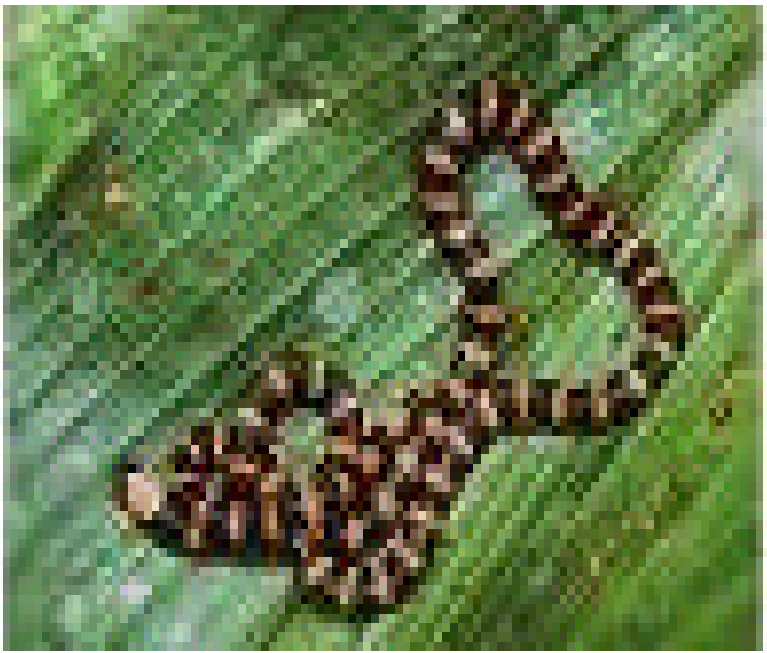

Micrurus multifasciatus

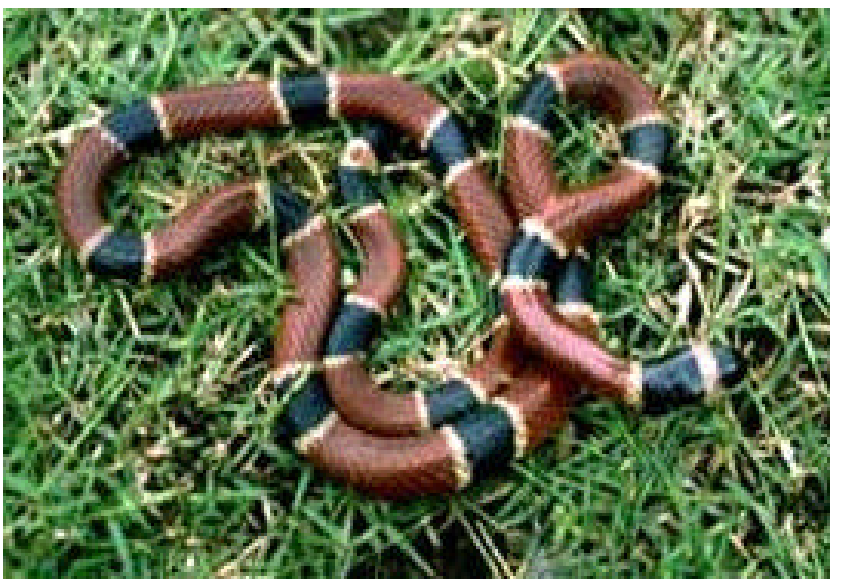

Micrurus nigrocinctus

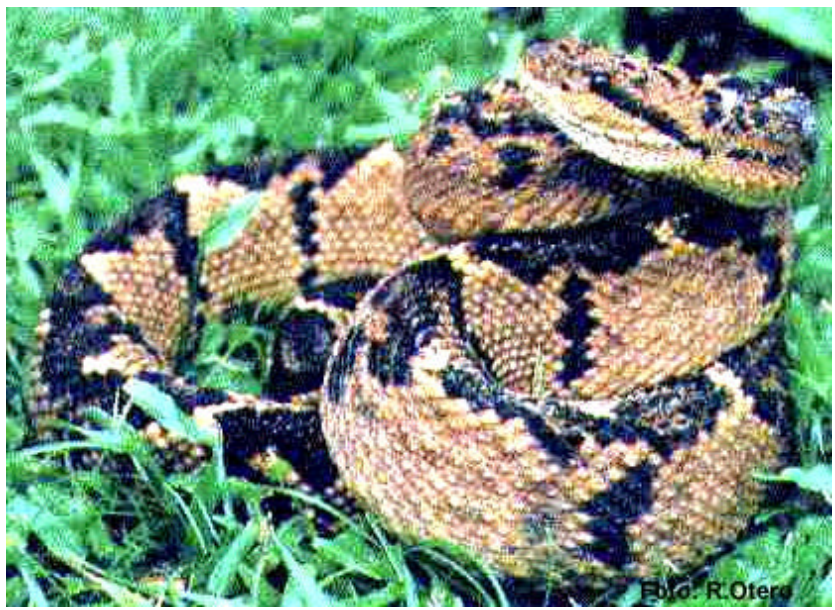

Lachesis muta

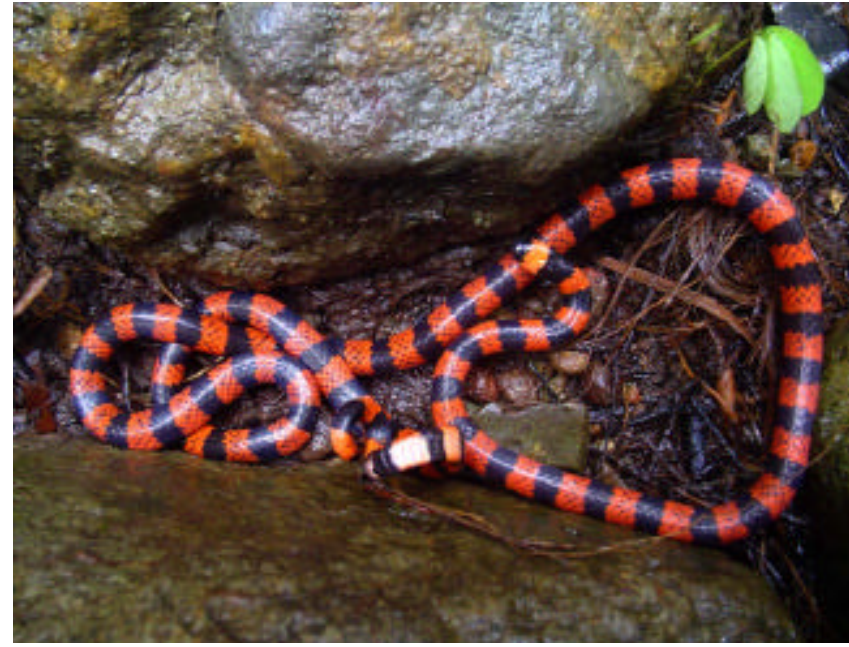

Micrurus multiscutatus

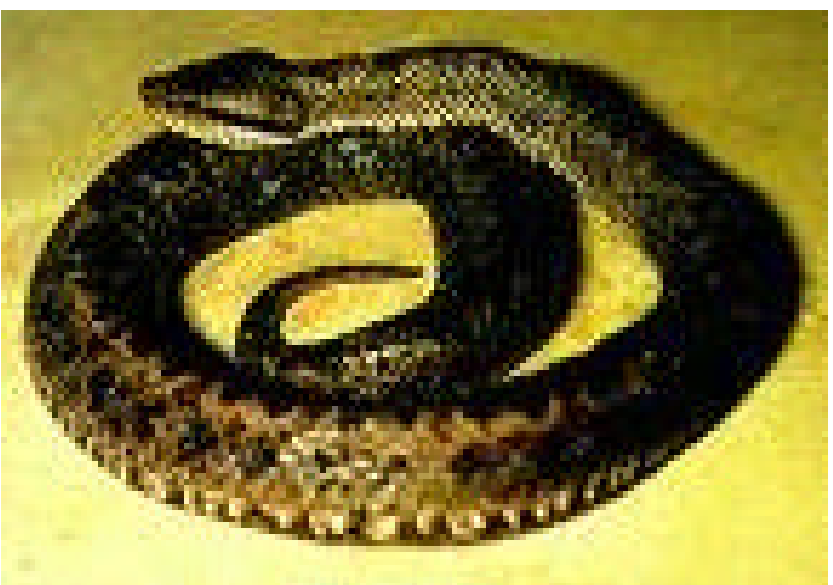

Micrurus spurrelli

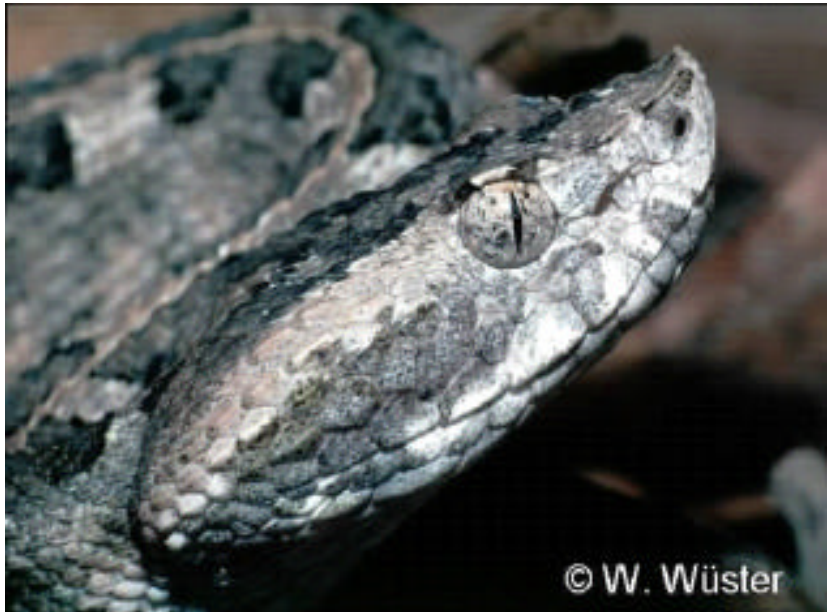

Porthidium lansbergii 


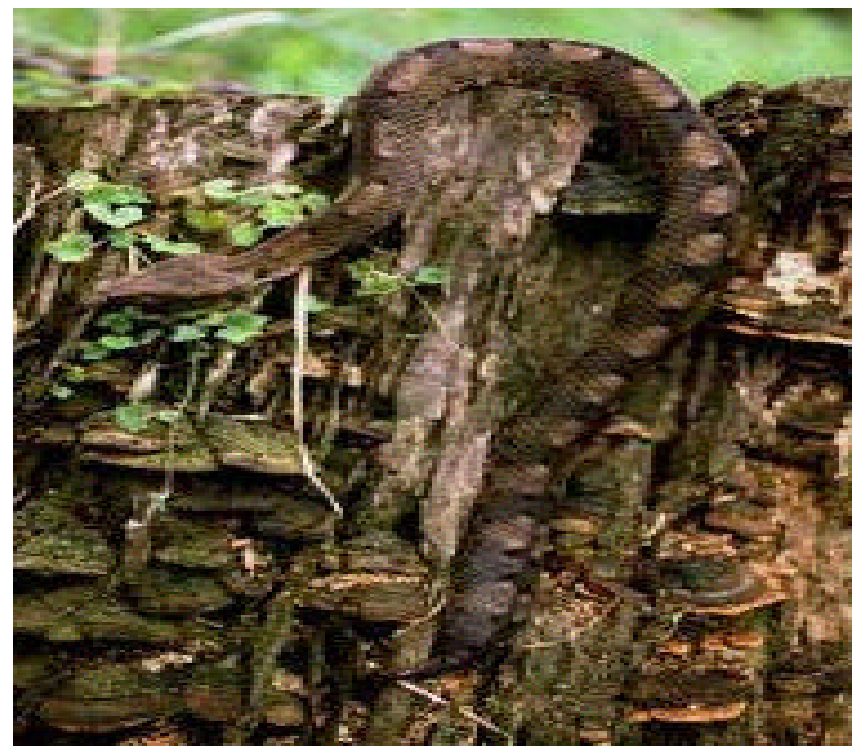

Porthidium nasutum

Bothrops asper. Descripción. El color de fondo es pardo claro o pardo rojizo, gris o rosáceo. Presenta un patrón dorsal de 18 a 25 manchas en forma de diamante bordeadas por líneas de escamas blancas y un centro más claro. Los ápices de los diamantes apuntan hacia la línea media del cuerpo y sus bases hacia el vientre dando un patrón en forma de «X» o de zigzag. La barbilla, el vientre y la cola son blanco amarillento o crema, tiene un cuerpo grueso. Es terrestre y nocturna, abundan en zonas de vegetación secundaria y acahuales, los cuales recorre en busca de roedores asociados con el hombre.Prefiere habitar en áreas húmedas hasta los $1150 \mathrm{msnm}$. Es común en la selva tropical perennifolia o zona de pastizal natural o inducido. Se le puede hallar en las horas del día enrollado entre la hojarasca de la selva o entre los troncos caídos. Se alimenta de vertebrados, sobre todo de roedores. Los juveniles predan sobre lagartijas, sapos y ranas, insectos y otros invertebrados, pero cambian sus hábitos alimenticios a mamíferos conforme maduran.

Distribución. Hace presencia en: Cau: Guapi: P.N.N. I. Gorgona, $25 \mathrm{~m}$, laguna cabrera, $90 \mathrm{~m}$. Puerto Merizalde, R. Naya, 100 m. Cho: Acandi, Lloró: Granja Universidad Tecnológica del Choco, «CIPAF»»[UTCH] (Rengifo, 2002). Quibdó: Corregimiento de Pacurita (Rengifo, 2002). Novita: 70 m. Nar: Tumaco: 2 m; Tangareal, 80 m, [UVC 5370] (Rangel 2004). Ris: Pueblo Rico: Corr. Santa Cecilia, La Granja, [ICN 6909] (Rangel 2004). VCau: Buenaventura: Atunceja, [UVC 11504] (Rangel 2004); Bahía Málaga, Cam. Lateral, Qda. Valencia, [UVC 8952]; Punta Soldado, EI Faro, [UVC 5355] (Rangel 2004).

Bothrocophias myersii. Descripción. Se dispersa entre los 100 y $200 \mathrm{msnm}$, el cuello es delgado, poseen una cola corta, sin cascabel en la punta, a falta de cascabel cuando están irritadas golpean la cola repetidamente; sus escamas son corenadas, habitan en zonas calurosas y un poco húmedas entre la leña, las hojas secas y los matorrales.

Distribución. Hace presencia en: Cau: R. Patía, Qda. Guangui, 100-200 m. Timbiquí: margen derecha del R.Timbiquí. VCau: Buenaventura: carr. Buenaventura - R. Calima, Qda. Caimancito, R. Cajambre, campamento №2,75 m. Bahía Málaga, Qda valencia,

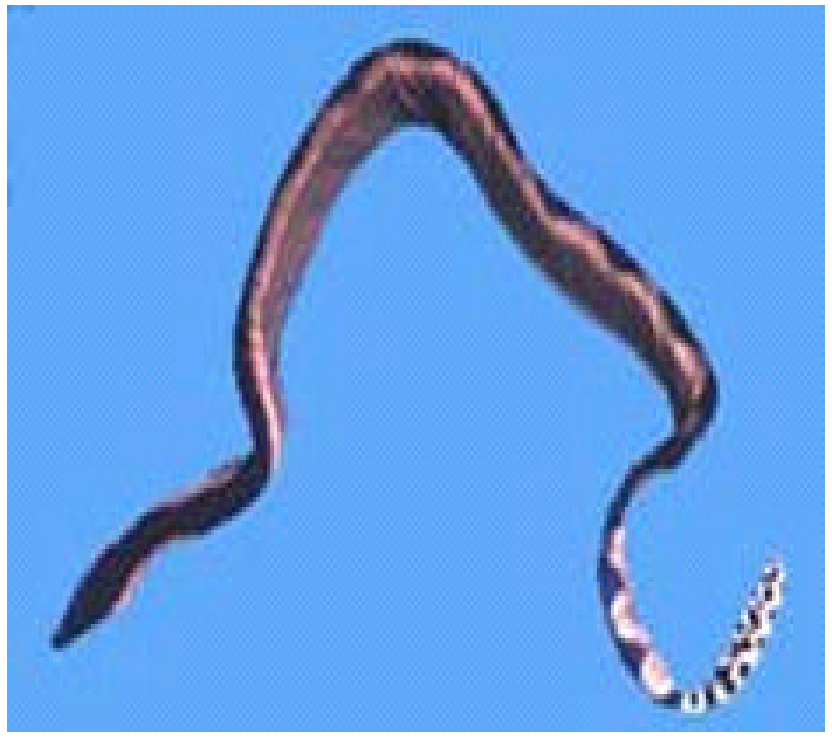

Pelamis platurus

Estero San Antonio, 15-50 m.

Bothriopsis punctata. Descripción. Poseen una cabeza subtriangular con una escama rostral más alta que ancha. Son de costumbres arborícolas de la zona tropical con una cola larga y prensil. Habitan en ambientes boscosos y enredadas en los árboles.

Distribución. Hace presencia en: Cau: sin localidad precisa .Cho: San José del palmar, 750m. Tado: Las Animas. Quibdó: Corr. Tutunendo (Renteria, 2006) [UTCH]. Nar: sin localidad precisa VCau: Buenaventura: Bajo Calima, Granja Agroforestal.

Bothrops punctatus. Descripción. Comúnmente conocida como rabo de chucha, llega a medir $130 \mathrm{~cm}$. Su coloración va desde pardo claro con manchas redondeadas en pares café oscura hasta verde amarillento; poco agresivas, semiarborícoras de hábitos nocturnos, se alimenta de aves y ranas. Hábitat en zonas de bosques húmedos y bosque pluvial tropical de 0 a $1200 \mathrm{msnm}$.

Distribución. Única especie reportada en Cho: Quibdó; Corregimiento de Tutunendo (Murillo \& Rengifo 2006).

Bothriechis schlegelii. Descripción. La cabeza es triangular, ancha y aplanada, bien diferenciada del cuello. Posee además el hocico arremangado. Su cola prensil le permite colgarse de cualquier rama, con un anillo colgante libre, gracias al cual puede lanzarse al ataque. Es relativamente delgado. Habita en la selva tropical perennifolia, sobre todo en zonas con poca perturbación. Acostumbra ser arborícola, nocturna y ocasionalmente se le encuentra asoleándose sobre las hojas y las ramas de los árboles. Cuando se le molesta asume una postura defensiva muy agresiva mientras abre la boca. Debido a sus hábitos arborícolas sus mordeduras ocurren casi siempre en partes superiores del cuerpo (Lee, 2000). Se alimenta de ranas, lagartos, pájaros y mamíferos pequeños. Tiene un aparato inoculador de veneno bastante desarrollado, con dos colmillos tubulares grandes y móviles (solenoglifas), los cuales están recubiertos por una membrana muy delgada. El veneno proviene de unas glándulas 


\section{Bioetnia Volumen 6 № 1 (enero-junio), 2009}

situadas detrás de los ojos (región temporal o postocular), las cuales son presionadas por el músculo temporal al producirse la mordedura, enviando el veneno a través de un conducto hacia los colmillos. A causa de la toxicidad del veneno, la mordedura puede ser fatal para el hombre.

Distribución. Hace presencia en los departamentos de: Cau: Puerto Naya. Cho: Alto Baudó: R. Amparrado, 805 m. Tadó: Las Ánimas. Nar: Tumaco: Estación Experimental La Mira, cnias. R. Mira, Cas. de Tangascal, 100 m, Tangareal. VCau: Buenaventura: Bajo Anchicayá, vía antigua Cali-Buenaventura, bajo Calima, Granja Agroforestal, R. Calima, 50 m. Campamento Cartón Colombia a 7 km del R. 80 m.

Micrurus ancoralis. Descripción. La cabeza es ancha y aplanada dorsalmente, ésta y el cuello presentan una coloración con manchas y líneas características. Desde la punta del hocico hasta la parte anterior de la zona parietal es rojo brillante, esto incluye las escamas que bordean el hocico y la región gular. Algunos ejemplares presentan manchas negras al frente de la cabeza, entre los orificios nasales. Es de hábitos terrestre y nocturno. Se oculta durante el día en grietas entre la vegetación, hojarasca y debajo de rocas o entre troncos podridos de árboles caídos. Se han visto durante el día en áreas con vegetación densa. Está más activo en los meses cálidos y durante la temporada de lluvias. Se alimenta de otras culebras pequeñas y anfisbénidos.

Distribución. Haciendo presencia en: Cau: Sin localidad precisa. Cho: Lloró: Granja Universidad Tecnológica del Chocó, «CIPAF»»[UTCH] (Rengifo, 2002). Quibdó: Corregimiento de Pacurita (Rengifo, 2002). Nar: Barbacoas: La Guayacana, 100 m, [UVC 11162]. (Rangel 2004) VCau: Buenaventura: Bajo Anchicayá, [UVC 5214]; (Rangel 2004) Cas. de Juanchaco, [UVC 8961]; (Rangel 2004) Qda. Caimancito, R. Cajambre, campamento $\mathrm{N}^{\circ} 2,75$ m, [UVC 7246]; (Rangel 2004) Qda. Sierpecita, km 88 a Buenaventura, 250 m, [UVC 7449]; (Rangel 2004).

Micrurus clarki.Descripción. La región frontal de la cabeza es negra así como la parte dorsal de la misma, los costados son blancos o amarillo claro. Las escamas de esta parte poseen pigmento negro. La coloración clara abarca la zona ventral de la boca y sube diagonalmente hacia la nuca pasando por detrás de los ojos. Posee un anillo negro delgado que no se une ventralmente. La cabeza no se distingue del cuello. Es primordialmente nocturno aunque en los bosques densos y selvas bien conservadas puede estar activo durante el día. Su actividad es dependiente de las condiciones ambientales, sobre todo de la humedad y la temperatura. La mayor parte de estas serpientes son encontradas en la temporada lluviosa. Se alimentan de vertebrados elongados, sobre todo de serpientes pequeñas, aunque también de lagartijas e incluso puede llegar a alimentarse de otras de su misma especie. Su veneno es neurotóxico y para estas mordeduras se requiere el uso específico anti-coral.

Distribución. Hace presencia en: Cau: Guapi: P.N.N.I. Gorgona, 15 m. Cho: Istmina: Corr. Andagoya, alto R. San Juan, 70 m. Río Sucio: P.N.N. Katios 900 m.Nar: sin localidad precisa.

Micrurus dissoleucus. Descripción. La forma alargada de la cabeza es una característica distintiva de esta especie. Ésta es negra en su parte frontal y dorsal, este color cubre de forma uniforme hasta la parte trasera de los ojos. Luego viene una banda blanca o anillo que cruza de lado a lado el dorso de la cabeza justo por detrás de los ojos. En algunos ejemplares la banda blanca está interrumpida, no llega hasta las escamas del borde del hocico o se presenta a manera de manchas blancas. El anillo nucal negro está después de esta banda blanca; en ocasiones el anillo nucal puede estar incompleto ventralmente. A este anillo le sigue un anillo rojo, después de éste comienza la primera tríada. Es de hábito cavícola, vive bajo tierra, ocupando las galerías de otros animales, también puede ser encontrada oculta bajo tocones grandes, troncos y otros objetos en el suelo. Se encuentra activa por la noche, de forma particular durante la temporada lluviosa. Se alimenta sobre todo de culebras. Las crías incorporan invertebrados y lagartijas. Habita hasta los $1000 \mathrm{msnm}$ en selva seca tropical, selva caducifolia, matorral espinoso, matorral costero, bosque montañoso bajo, bosques húmedos, llanos y sabanas. La mayor parte de los registros ha sido en zonas secas y estacionales.

Distribución. Sólo está reportada en: Cho: Medio San Juan: Andagoya, $65 \mathrm{~m}$.

Micrurus dumerilii. Descripción. Llega a medir entre 50 y 70 cm de longitud. En el cuerpo presenta el típico patrón tricolor con 10-27 anillos negros o más de 14 tríadas presentando el rojoamarillo-negro. La cola tiene anillos alternados blanco y negro que son más anchos. Algunos ejemplares son completamente rojos y sólo con anillos negros. El hocico y el dorso de la cabeza son negros formando una capucha, seguidos de un anillo amarillo o blanco en la región occipital que puede incluir las últimas escamas del hocico. Después tiene un anillo negro en la nuca que puede variar en grosor e incluso estar incompleto o ausente en ciertas poblaciones. Es de hábitos nocturno, terrestre y cavícola. Vive enterrado, en las madrigueras de otros animales o en oquedades naturales. Es muy raro verlo, aunque en ocasiones sale para alimentarse o buscar pareja. Se encuentra activo en los períodos de lluvia o de mayor humedad en su área de distribución. Se alimenta de culebras terrestre, incluso de otras corales, ocasionalmente lagartijas y anguilas. A su vez, son presa de otras serpientes, mamíferos y algunas aves rapaces. Al sentirse en peligro o amenazado, deja su cabeza debajo de alguna parte de su cuerpo y levanta la punta de la cola mostrando sus colores brillantes en forma de advertencia.

Distribución. Hace presencia en: Cho: Bahía Solano: Mecana, [UVC 5399]. (Rangel 2004). Quibdó: Tutunendo [UTCH] (Murillo, 2004) Lloró: Granja Universidad Tecnológica del Chocó, «CIPAF». [UTCH]. Corregimiento de Pacurita (Rengifo, 2002). San José de Purre (Murillo, 2004) Nuquí: Vda. La Cuevita, [UVC 10783]. (Rangel 2004) San José del Palmar: Playa Rica, trocha al Torra, 200 m, [UVC 7347]. (Rangel 2004) Tadó: Vda. Marmolejo, 470 ni, [ICN 6964]. (Rangel 2004). VCau: Buenaventura: Bahía Málaga, Cam. lateral, Qda. Valencia, [UVC 8950]; (Rangel 2004) Bajo Anchicayá, Vda. Guamia; [UVC 13675]; (Rangel 2004) Bajo.

Micrurus mipartitus. Descripción. La cabeza es negra y cubre hasta la parte posterior de los ojos, luego inicia un anillo rojo o anaranjado amplio, distintivo de la especie, que se une con el anillo nucal negro. Es de hábito terrestre. Vive en el suelo, oculto entre la maleza, hojarasca, debajo de rocas y troncos de árboles caídos. Se alimenta de otras serpientes como Atractus werneri y A. sanctamartae, serpientes ciegas Leptotyphlops spp., anfisbénidos, lagartijas y cecilias.

Distribución. Se encuentra en: Cau: Guapi: P.N.N.I. Gorgona, 15 m. Cho: Istmina: Corr. Andagoya, alto R. San Juan, 70m. Río Sucio: P.N.N. Katios 900 m.Nar: sin localidad precisa. 


\section{Ataques de ofidios venenosos. R. Martínez, K. Machado}

Micrurus multifasciatus. Descripción. El hocico es completamente negro y este color abarca la parte superior de la cabeza y los costados hasta detrás de los ojos. Después se observa un anillo ancho y claro que puede ser rojo, rosa, anaranjado o blanco en la parte trasera de la cabeza. Es de hábitos terrestre y crepuscular, aunque se lo encuentra también por la mañana. Vive entre la hojarasca, bajo troncos y en oquedades en el suelo, sólo emerge a la superficie ocasionalmente para alimentarse. Su actividad aumenta al inicio y durante la época de lluvias en los distintos sitios en los que habita. Se alimenta de pequeñas culebras, serpientes ciegas y cecilias. Habita hasta los 1550 msnm en selva tropical lluviosa, selva húmeda subtropical y bosque subtropical montañoso.

Distribución. Hace presencia solo en: VCau: Darién, Campo Alegre, [UVC 6676] (Rangel 2004).

Micrurus multiscutatus. Descripción.La cabeza pequeña, no se diferencia del cuello y desde la escama rostral hasta los ojos es negra, el resto es de color rojo. Los parietales, en ocasiones, pueden ser amarillos. Presenta 15 hileras longitudinales de escamas lisas y sin fosa apical en la mitad del cuerpo; 305 escamas ventrales y 28 subcaudales divididas. La escama anal se encuentra dividida. Es de hábitos terrestre, semi-excavador, nocturno y crepuscular. Se puede encontrar en zonas boscosas, cerca de corrientes de aguas y durante el día después de fuertes lluvias, porque la superficie del suelo se inunda y debe subir a respirar. Es principalmente ofiófago, aunque también puede alimentarse de otros animales de forma alargada como lagartos y cecilias. Es altamente venenoso. Habita hasta los 1000 msnm en bosque húmedo, muy húmedo $\mathrm{y}$ pluvial tropical $\mathrm{y}$ tramontano.

Distribución. Hace presencia en: Cau: Timbiquí: Qda. Guangui, R. Saija, 5 m. VCau: Buenaventura: Bajo Calima, Cartón Colombia, [UVC 5207]; (Rangel 2004): Cho: Atrato: San José de Purre (Murillo, 2004) [UTCH].

Micrurus nigrocinctus. Descripción. La cabeza puede ser negra en su parte anterior, cubriendo sólo el hocico o ir hasta la parte trasera de los ojos. Luego se presenta un anillo amarillo claro, con anchos variables dependiendo del pigmento negro de la cabeza y del anillo nucal negro que se inicia después de éste. Es de hábitos crepuscular, nocturno y terrestre. En ocasiones se encuentra activo durante el día. Generalmente está oculto en huecos del suelo, entre raíces, hojarasca, bajo rocas o troncos caídos. Al sentirse en peligro o amenazado, coloca su cabeza debajo de alguna parte de su cuerpo y levanta la punta de la cola mostrando sus colores en forma de advertencia o bien para que el atacante no sepa cuál es la cabeza. Se alimentación de muy variada. Preda serpientes ciegas, Anomalepis mexicanus, Helminthophos sp., culebras, Ninia maculata, N. sebae, Coniophanes spp., C. fissidens, Geophis dunni, G. nasalis, Adelphicos quadrivirgatus, Rhadinaea godmani, Tantilla spp., Leptodeira nigrofasciata, Drymobius margaritiferus, serpientes venenosas, Porthidium ophryomegas, lagartijas y huevos de las mismas. Es presa de otras serpientes, aves rapaces y mamíferos como el zorrillo. Habita hasta los mil cuatrocientos metros sobre el nivel del mar en una gran variedad de tipos de vegetación, como selva tropical lluviosa, selva seca o caducifolia, bosque montañoso húmedo y bosque montañoso seco, hasta, ocasionalmente en bosque de niebla.

Distribución. Hace presencia en: Ant: Turbo: R. Currulao, 20 m, [ICN 1945] (Rangel 2004).

Micrurus spurrelli. Descripción. La cabeza pequeña, no se diferencia del cuello. Es bicolor. La parte frontal del hocico es negra, luego viene una angosta banda blanca entre la nariz y el frente de los ojos que puede ser continua o estar dividida por una banda blanca en la parte media del dorso de la cabeza. Esta línea puede extenderse dorsalmente hasta la punta del hocico. A nivel de los ojos tiene otro anillo negro más o menos ancho seguido de uno blanco, anterior al anillo negro en la nuca. Ventralmente la cabeza es blanca con excepción de las escamas próximas al hocico. Es de hábitos terrestre, semiminador o barrenador y nocturno. Se pude encontrar debajo de la maleza, la hojarasca de la selva, bajo rocas o bien entre troncos caídos en descomposición. Después de las lluvias es posible hallarlo de día. Se alimenta de culebras pequeñas de su misma especie y otros pequeños animales que viven en el suelo. Habita hasta los $400 \mathrm{~m}$ sobre el nivel del mar en selva tropical lluviosa.

Distribución. Hace presencia sólo en: Cho: Condoto: Pena Lisa, 70 m. Istmina: [UVC 5417] (Rangel 2004).

Lachesis muta. Descripción. Es el gigante de las víboras de fosa americanas y una de las especies venenosas más largas del mundo. Puede superar los $3.60 \mathrm{~m}$. Se han observado ejemplares que superan los $4.10 \mathrm{~m}$. El color característico va del amarillo a un marrón oscuro, con manchas como diamante, que son más oscuras en su parte posterior. Su vientre es anaranjado o blanco. Su alimento consiste, principalmente, de mamíferos pequeños, a los cuales acecha en los senderos de la selva. Aunque es, por lo general un predador silencioso, cuando está amenazado, puede sacudir su cola e inflar su cuello. Se encuentra siempre en el suelo, por lo común enroscada entre el espesor de la vegetación del bosque bajo, consigue un perfecto mimetismo con el ambiente en el cual se desenvuelve. Habita en los bosques tropicales sobre todo en las cercanías de los ríos o de las aguas estancadas.

Distribución. Hace presencia: Cau: Guapi [UVC5440]. (Rangel 2004) Cho: Novita: El Naranjo, límites con el Valle, [UVC 854]. (Rangel 2004). Tutunendo [UTCH], Lloró: Granja Universidad Tecnológica del Chocó,»CIPAF»[UTCH]. Corregimiento de Pacurita (Rengifo, 2002). Nar: sin localidad precisa VCau: Buenaventura: Bajo R. Calima, Campamento Cartón de Colombia. Carr, hacia Buenaventura, 45 m [ICN 1368]; R. Anchicaya, 300 m. [ICN 1474]; (Rangel 2004) R. Calima, 50 m. [ICN 301]. (Rangel 2004).

Porthidium lansbergii. Descripción. Mide entre 40 y $60 \mathrm{~cm}$ de longitud. Habita en desiertos y prados entre los 1000 y $3000 \mathrm{msnm}$. Se alimenta de ratones, ratas, lagartijas y aves. Es de hábitos terrestres y marcadamente nocturnos; pasa la mayor parte del tiempo entre la hojarasca o bien bajo troncos caídos; es abundante en temporadas lluviosas.

Distribución. Hace presencia en: Ant: Mutata: cnins, Villa Arteaga, Zona Cauchera, región de Turbo, 80m [ICN 54]. (Rangel 2004) Cho: Vert. Del R. San Juan.

Porthidium nasutum. Descripción. Posee un color marrón y negro oscuro, pardo o canela, alternado en manchas irregulares. Tiene una línea pálida en el centro de la parte posterior que divide una serie de 15 a 23 manchas rectangulares o triangulares que recorren su cuerpo. En juveniles, la punta de la cola es amarillenta. De cabeza triangular diferenciada del cuello y pupilas verticales elípticas. Se caracteriza por su hocico respingón, por lo menos dos veces más alto que ancho, que recuerda notablemente el de la víbora del cuerno, Vipera ammodytes, propia del continente europeo. Puede ser nocturno o diurno y por su coloración es casi imperceptible en el 


\section{Bioetnia Volumen 6 № 1 (enero-junio), 2009}

suelo de la selva. Se le encuentra con frecuencia entre la hojarasca mientras toma el sol. En ocasiones trepa arbustos y matorrales a más de un metro del suelo. Prefiere las zonas de selva poco perturbadas. Habita principalmente en regiones húmedas de las montañas y bosques de lluvia. Su veneno es de escasa toxicidad.

Distribución. Hace presencia en los departamentos de: Ant: Turbo: R. currulao, 20 m [ICN 1952]. (Rangel 2004) Cau: sin localidad precisa. Cho: Lloró; Granja Universidad Tecnológica del Chocó, «CIPAF» [UTCH] (Rengifo, 2002). Quibdó: Corregimiento de Pacurita (Rengifo, 2002).Corr. Tutunendo (Rentería, 2006) [UTCH]. Nar: sin localidad precisa. Vcau: Buenaventura: Bajo Anchicayá. Vda. Guamia [UVC 13672]; (Rangel 2004) Bajo Calima, Qda. La Brea [UVC 6650]; (Rangel 2004) Bajo R. Calima, 10-40 m, [ICN 411]; (Rangel 2004) Corr. Barco. R. Cajambre, 50 m [UVC 7242]; (Rangel 2004) Granja 630 Agroforestal, [UVC 7626]; (Rangel 2004) Palmeras del Pacífico, 10 m [UVC 7435]; (Rangel 2004) R. Cajambre, 15 m, [ICN 42]; (Rangel 2004) R. Calima, 50 m [ICN 299]; (Rangel 2004) Campamento Cartón Colombia, a 7 km del R., 80 m [ICN 397] (Rangel 2004).
Pelamis platurus. Descripción.Es de color pardo negruzco oscuro por la parte superior del cuerpo y amarillo brillante por la parte inferior. Los dos colores se juntan en una línea bien definida. Esa coloración se presenta en casi todas las partes donde se encuentre esta especie. En otras regiones aparece una gran diversidad de esquemas y los colores están a veces interrumpidos por franjas transversales alternas. Se alimenta enteramente en la superficie. Tiene una boca pequeña y un par de colmillos frontales fijos ubicados en el maxilar superior (Proteroglifa). Se sabe que en su ambiente natural como en cautiverio, no es una especie agresiva, produce poca cantidad de veneno, pero de alta toxicidad. Se debe ser en extremo prudente al manipularlo. Vive especialmente en el océano Pacífico, en bahías y golfos, entre uno y tres kilómetros de la costa. El hecho que esta especie nada con facilidad a mar abierto contribuye a explicar su gran distribución.

Distribución. Hace presencia en:Cau: Guapi: P.N.N. I. Gorgona, N. de la isla de la playa, [ICN 481]. (Rangel 2004)Cho: Juradó: Cabo Marzo, [ICN 1292]. (Rangel 2004) VCau: Buenaventura: [ICN 1883]; (Rangel 2004) Juanchaco, [UVC 6748] (Rangel 2004). 